\section{Far-red Light Absorbing Photoselective Plastic Films Affect Growth and Flowering of Chrysanthemum Cultivars}

\author{
Shumin Li and Nihal C. Rajapakse ${ }^{1}$ \\ Department of Horticulture, Clemson University, Clemson, SC 29634
}

\section{Roy E. Young ${ }^{2}$ \\ Department of Agricultural and Biological Engineering, Clemson University, Clemson, SC 29634 \\ Additional index words. spectral filters, R : FR ratios, photomorphogenesis, plant growth regulation}

\begin{abstract}
Growth and development responses of three chrysanthemum [Dendranthema × grandiflora (Ramat.) Kitam. (syn. Chrysanthemum xmorifolium Ramat.)] cultivars ('Bright Golden Anne', 'Iridon', and 'Yellow Snowdon') to photoselective plastic films with varying concentrations $\left(0\right.$ to $0.22 \mathrm{~g} \cdot \mathrm{m}^{-2}$ ) of a far-red (FR) light absorbing dye were investigated under greenhouse conditions. Photoselective films reduced stem elongation of all three cultivars. The greater the dye concentration in the film, the greater and earlier the reduction in stem elongation. After 4 weeks, 'Yellow Snowden', 'Bright Golden Anne', and 'Iridon' plants grown under the film with the highest dye concentration $\left(A_{\text {fr } 3}\right.$ film) were $21 \%, 26 \%$, and $26 \%$ shorter than control plants, respectively. Height reduction under photoselective films was caused by shorter internodes. Photoselective covers were most effective in reducing the stem elongation during the early vegetative period. Following transition to the reproductive stage, weekly stem elongation rates were reduced. At the time of flowering, 'Yellow Snowden', 'Bright Golden Anne', and 'Iridon' plants grown under the film with the highest dye concentration $\left(A_{\text {fr } 3}\right.$ film) were $12 \%, 7 \%$, and $14 \%$ shorter than control plants, respectively. Photoselective covers did not affect the anthesis of chrysanthemum cultivars, but resulted in a $10 \%$ to $14 \%$ reduction in flower diameter depending on the cultivar. Although the films with higher dye concentration were more effective in reducing stem elongation of chrysanthemum, increased dye concentration reduced light transmission. Thus, photoselective covers that reduce light transmission over $25 \%$ would not be suitable for commercial production.
\end{abstract}

Plants perceive changes in red $[(\mathrm{R}), 600$ to $700 \mathrm{~nm}$ ] and far-red [(FR), 700 to $800 \mathrm{~nm}$ ] light composition via phytochrome and make physiological and morphological adjustments to suit the environmental conditions. Red and FR light are known to inhibit and promote stem elongation of seedlings, respectively. In general, environments high in $\mathrm{R}$ light relative to FR light are favorable for production of short and compact plants. Takaichi et al. (2000) reported that muskmelon (Cucumis melo L.), tomato (Lycopersicon esculentum Mill.), and cucumber (Cucumis sativus L.) seedling height decreased linearly as the average $\mathrm{R}$ : FR ratio increased.

Manipulation of greenhouse light environment has been investigated as an alternative

Received for publication 17 July 2000. Accepted for publication 24 June 2002. Technical contribution No. 4790 of the South Carolina Agricultural Experiment Station, Clemson Univ. We thank J.R. Rieck for his advice in experimental design and data analysis.

${ }^{1}$ To whom reprint requests should be addressed. Tel.: 1-864-656-4970; Fax: 1-864-656-4960; E-mail adress: NRJPKS@clemson.edu

${ }^{2}$ Current address: Dept. of Agricultural and Biological Engineering, The Pennsylvania State Univ., University Park, PA 16802-1909. for chemical growth regulation of vegetable and ornamental transplants. Most early work was done with liquid filters that can alter light composition in a greenhouse. Of the different filters tested, liquid $\mathrm{CuSO}_{4}$ filters were effective in removing FR light from the sunlight and in reducing stem elongation of a wide range of dicotyledonous plants (McMahon et al., 1991; Mortensen and Strømme, 1987; Rajapakse and Kelly, 1992). However, liquid spectral filters have limited value commercially because of difficulty in handling in commercial greenhouse operations.

The development of plastic photoselective greenhouse covers could facilitate the use of commercial greenhouse light manipulation for height control. Currently, such greenhouse covers are not commercially available, but several research teams are interested in developing photoselective films. Murakami et al. (1996 and 1997) reported rigid plastic panels with FR light intercepting pigments reduced height but delayed harvesting of cucumber, tomato, and sunflower (Helianthus annuus L.) plants, and panels with $\mathrm{R}$ light intercepting pigments produced taller plants and earlier harvesting. van Haeringen et al. (1998) found that a FR light absorbing film reduced chrysanthemum height by $14 \%$ compared to nonselective plastic films, but the number of nodes below inflorescence and time of flowering were not altered. In our work, FR light absorbing photoselective films effectively reduced height of several crops, but the effectiveness varied with species (Li et al., 2000; Rajapakse et al., 1999). To be commercially attractive, photoselective films should be effective on a wide range of crops and cultivars. To our knowledge, information on variety and cultivar responses to photoselective films is limited. In this paper, we report the growth and flowering responses of three chrysanthemum cultivars under photoselective films with various dye concentrations. Understanding the plant response to photoselective films with varying dye concentration would aid in the selection of a suitable dye concentration to be used in photoselective covering material for commercial use.

\section{Materials and Methods}

Photoselective films. Polyethylene films with four concentrations of a FR light absorbing dye were produced by Mitsui Chemicals, Tokyo. These films were identified by the following code names: control (dye at $0 \mathrm{~g} \cdot \mathrm{m}^{-2}$ ), $\mathrm{A}_{\text {fri }}$ (dye at $\left.0.08 \mathrm{~g} \cdot \mathrm{m}^{-2}\right), \mathrm{A}_{\text {fr } 2}$ (dye at $0.13 \mathrm{~g} \cdot \mathrm{m}^{-2}$ ), and $\mathrm{A}_{\mathrm{fr} 3}$ (dye at $0.22 \mathrm{~g} \cdot \mathrm{m}^{-2}$ ). Four PVC-framed growth chambers $(1.2 \mathrm{~m} \times 1.2 \mathrm{~m} \times 1.3 \mathrm{~m}$; one for each film) were covered with these films. $\mathrm{A} \mathrm{CuSO}_{4}$ liquid filter (4\%) chamber with the same dimension was included as a comparison. In each chamber, two fans (one attached to the lower left corner and the other attached to the upper right corner of the opposite side) were oriented in the same direction for airflow and to prevent heat buildup. Photosynthetic photon flux $(P P F)$ transmission of the control film was $\approx 90 \%$ and that for $\mathrm{CuSO}_{4}$ was $\approx 75 \%$. The PPF transmission of $\mathrm{A}_{\mathrm{fr} 1}, \mathrm{~A}_{\mathrm{fr} 2}$, and $\mathrm{A}_{\mathrm{fr} 3}$ films were $80 \%, 75 \%$, and $65 \%$, respectively. All growth chambers were placed inside a glass greenhouse.

The $P P F$ inside growth chambers was measured biweekly (at five locations within each chamber) between 1200 and 1400 HR on clear days with a LI-185 quantum meter fitted with a LI-190SA quantum sensor (LI-COR, Lincoln, Nebr.). The $P P F$ was adjusted with cheesecloth to be similar among all chambers before plant placement of in chambers. Spectral distribution in $10 \mathrm{~nm}$ increments from 330 to $1100 \mathrm{~nm}$ was measured at the middle of each chamber with a LI- 1800 spectroradiometer fitted with a LI-1800-10 remote cosine sensor at the beginning and end of the experiments. The cheesecloth did not alter the quality of light transmitted. Multiple light scans within a chamber indicated that the spectral distribution was uniform inside the chamber. The $\mathrm{R}$ : FR ratio was determined as the ratio of photon flux density between 600 and $700 \mathrm{~nm}(\mathrm{R})$ and 700 and $800 \mathrm{~nm}$ (FR). Phytochrome photoequilibrium (ratio of active $\mathrm{P}\left[\mathrm{P}_{\mathrm{fr}}\right]$ to total $\mathrm{P}\left[\mathrm{P}_{\text {total }}\right]$ ) was estimated from spectral energy distribution data as described by Sager et al. (1988).

Plant material and culture. Chrysanthemum 'Bright Golden Anne', 'Iridon', and 'Yellow Snowdon' were used in the experiments. Uniform, rooted shoot cuttings with 
three to four leaves were planted individually in 2-L pots containing a commercial potting mix (Metro Mix-360; Scotts-Sierra Horticultural Products Co., Marysville, Ohio). Plants were allowed to establish in a glasshouse as single stem plants for 1 week before transferring to the experimental chambers. Average initial height of cuttings was $\approx 4.0 \mathrm{~cm}$. Plants of three cultivars were grown $(\approx 20 \mathrm{~cm}$ apart $)$ in the experimental chambers until the first flower on the main stem of all plants was fully open (six to seven petal layers open). Plants were fertilized three times a week at irrigation with $1 \mathrm{~g} \cdot \mathrm{L}^{-1}$ of a $20 \mathrm{~N}-4.4 \mathrm{P}-16.7 \mathrm{~K}$ water soluble fertilizer (Peters 20-10-20 Peat-Lite Special; Scotts-Sierra Horticultural Products Co.). Due to the limited number of chambers, the experiment was repeated for replication. The average natural photoperiods during the first and repeat experiments were $10.5 \pm 0.5 \mathrm{~h}$ (SD) and $11.5 \pm 1.0 \mathrm{~h}(\mathrm{SD})$. The daily maximum or minimum temperatures (as recorded with maximum/minimum thermometers) were not different among experimental chambers, which averaged $30 \pm 2{ }^{\circ} \mathrm{C}$ and $16 \pm 1{ }^{\circ} \mathrm{C}$ during first experiment and $32 \pm 2^{\circ} \mathrm{C}$ and $21 \pm 1^{\circ} \mathrm{C}$ during second experiment, respectively. The average maximum $P P F$ inside chambers was $400 \pm$ 50 and $600 \pm 75 \mu \mathrm{mol} \cdot \mathrm{m}^{-2} \cdot \mathrm{s}^{-1}$ during first and second experiment on clear days.

Experimental design, data collection, and analyses. Experimental chambers were randomly placed inside a glass greenhouse. The experimental design was a randomized complete-block design with a split-plot arrangement. The light treatment was the whole plot factor. Three cultivars (10 plants/cultivar/ light treatment) were the subplot factors. Sets of 10 plants were the experimental units for the subplot factor and groups of cultivars were the experimental units for the whole plot factor.

Plant height (height from soil level to apex) and number of fully expanded leaves were recorded weekly. Number of days to anthesis were recorded. At the end of the experiment, numbers of lateral branches and flower buds, and diameter of the apical flower were recorded. Data were subjected to analysis of variance and treatment differences were separated using Duncan's multiple range test at $P=0.05$.

\section{Results and Discussion}

Light quality. The dye in films absorbed FR light with maximum absorption at $760 \mathrm{~nm}$ (Li et al., 2000). FR light absorption of films increased with increased dye concentration. The $\mathrm{CuSO}_{4}$ liquid filter absorbed almost all wavelengths beyond $700 \mathrm{~nm}$. The R : FR ratio inside control, $\mathrm{A}_{\mathrm{fr} 1}, \mathrm{~A}_{\mathrm{fr} 2}, \mathrm{~A}_{\mathrm{fr} 3}$, and $\mathrm{CuSO}_{4}$ chambers were $1.1,1.6,2.3,3.5$, and 3.7 , respectively. The $\mathrm{P}_{\mathrm{fr}} / \mathrm{P}_{\text {total }}$ inside control, $\mathrm{A}_{\text {fr } 1}$, $\mathrm{A}_{\mathrm{fr}}, \mathrm{A}_{\mathrm{fr} \cdot \mathrm{r}}$, and $\mathrm{CuSO}_{4}$ chambers were 0.72, 0.75, $0.78,0.81$, and 0.80 , respectively.

Chrysanthemum growth under photoselective films. After 4 weeks under treatments, plants of all three chrysanthemum cultivars grown inside photoselective film chambers were shorter than control plants (Table 1). Plant height decreased as the $\mathrm{R}$ : FR ratio increased. After 4 weeks under

Table 1. Influence of far-red light absorbing films on plant height, number of leaves, and average internode length of the three chrysanthemum cultivars. Each number is the average of 20 plants taken after 4 weeks of exposure to photoselective films. Number in parenthesis followed by the plant height indicates the percentage of height relative to control plants.

\begin{tabular}{|c|c|c|c|c|}
\hline Treatment $^{2}$ & $\begin{array}{c}\mathrm{R}: \mathrm{FR} \\
\text { ratio }\end{array}$ & $\begin{array}{l}\text { Plant height } \\
(\mathrm{cm})\end{array}$ & $\begin{array}{c}\text { Node } \\
\text { no. }\end{array}$ & $\begin{array}{l}\text { Avg internode } \\
\text { length }(\mathrm{cm})\end{array}$ \\
\hline \multicolumn{5}{|c|}{ Bright Golden Anne } \\
\hline Control & 1.1 & $20.7 \mathrm{a}^{\mathrm{y}}(100)$ & $18 \mathrm{a}$ & $1.07 \mathrm{a}$ \\
\hline $\mathrm{A}_{\mathrm{fr} 1}$ & 1.6 & $17.8 \mathrm{~b}(86)$ & $18 \mathrm{a}$ & $0.97 \mathrm{~b}$ \\
\hline$A_{\text {fr2 } 2}$ & 2.3 & $17.2 \mathrm{~b}(83)$ & $19 \mathrm{a}$ & $0.91 \mathrm{bc}$ \\
\hline $\mathrm{A}_{\mathrm{fr} 2}$ & 3.5 & 15.4 c (74) & $18 \mathrm{a}$ & $0.83 \mathrm{c}$ \\
\hline $4 \% \mathrm{CuSO}_{4}$ & 3.7 & $14.7 \mathrm{c}(71)$ & $18 \mathrm{a}$ & $0.82 \mathrm{c}$ \\
\hline \multicolumn{5}{|c|}{ Iridon } \\
\hline Control & 1.1 & 14.6 a $(100)$ & $20 \mathrm{a}$ & $0.71 \mathrm{a}$ \\
\hline $\mathrm{A}_{\mathrm{fr} 1}$ & 1.6 & $13.2 \mathrm{ab}(90)$ & $21 \mathrm{a}$ & $0.63 \mathrm{~b}$ \\
\hline $\mathrm{A}_{\mathrm{fr} 2}$ & 2.3 & 11.4 b (78) & $20 \mathrm{a}$ & $0.55 \mathrm{c}$ \\
\hline $\mathrm{A}_{\mathrm{fr} 3}^{\mathrm{fr} 2}$ & 3.5 & 10.8 b (74) & $20 \mathrm{a}$ & $0.52 \mathrm{c}$ \\
\hline $4 \% \mathrm{CuSO}_{4}$ & 3.7 & $10.9 \mathrm{~b}(75)$ & $21 \mathrm{a}$ & $0.52 \mathrm{c}$ \\
\hline \multicolumn{5}{|c|}{ Yellow Snowdon } \\
\hline Control & 1.1 & $32.1 \mathrm{a}(100)$ & $21 \mathrm{a}$ & $1.53 \mathrm{a}$ \\
\hline $\mathrm{A}_{\mathrm{fr} 1}$ & 1.6 & 30.3 a (94) & $21 \mathrm{a}$ & $1.44 \mathrm{~b}$ \\
\hline $\mathrm{A}_{\mathrm{fr} 2}^{\mathrm{II1}}$ & 2.3 & $27.6 \mathrm{~b}(86)$ & $20 \mathrm{a}$ & $1.36 \mathrm{bc}$ \\
\hline $\mathrm{A}_{\mathrm{fr} 3}^{\mathrm{Ir}}$ & 3.5 & $25.3 \mathrm{~b}(79)$ & $20 \mathrm{a}$ & $1.27 \mathrm{c}$ \\
\hline $4 \% \mathrm{CuSO}_{4}$ & 3.7 & $26.1 \mathrm{~b}(81)$ & $20 \mathrm{a}$ & $1.28 \mathrm{c}$ \\
\hline
\end{tabular}

treatments, 'Yellow Snowden', 'Bright Golden Anne', and 'Iridon' plants grown inside $\mathrm{A}_{\mathrm{fr} 3}$ chamber were $21 \%, 26 \%$, and $26 \%$ shorter than control plants, respectively. Number of leaves was not affected, so height reduction under photoselective films was caused by shorter internodes.

Reduction in stem elongation was evident as early as 2 weeks of exposure to experimental films (Fig. 1). The higher the $\mathrm{R}$ : FR ratio (or $\mathrm{P}_{\mathrm{fr}} / \mathrm{P}_{\text {total }}$ ) the earlier and greater the inhibition of stem elongation. For example, 'Bright Golden Anne' plants in the $\mathrm{A}_{\mathrm{fr} 3}$ chamber ( $\mathrm{R}$ : FR ratio of 3.5) were shorter than control plants after 2 weeks in treatments, but in the $\mathrm{A}_{\mathrm{frr} 1}$, and $\mathrm{A}_{\mathrm{fr} 2}$ chambers (R: FR of 1.6 and 2.3, respectively) it was not evident until after 3 weeks.

The inhibition of stem elongation by photoselective films was greatest during 3 to 5 weeks of the treatment period, depending on the cultivar and film type (Fig. 1). Following this period, weekly stem elongation rates were not significantly different among treatments (or in some cases the weekly stem elongation rate was higher under photoselective films). As a result, the difference in plant height at flowering between control and photoselective film grown plants was reduced (Table 2 ). For example, after 4 weeks of treatment 'Bright Golden Anne' plants grown in $\mathrm{A}_{\mathrm{fr} 1}, \mathrm{~A}_{\mathrm{fr} 2}, \mathrm{~A}_{\mathrm{fr}, 3}$, and $\mathrm{CuSO}_{4}$ chambers were $14 \%, 17 \%, 26 \%$, and $29 \%$ shorter than control plants, respectively. However, at the time of flowering (after 10 weeks of treatment) the respective plants were only $5 \%, 8 \%, 12 \%$, and $18 \%$ shorter than control plants. A similar trend was found in 'Yellow Snowden' and 'Iridon' cultivars. This suggests that photoselective films were most effective in reducing the stem elongation during the early vegetative period. Once the chrysanthemum plants reach reproductive stage, stem growth slows down and effectiveness of films is reduced. Morgan and Smith $(1976,1979)$ reported that young Chenopodium album seedlings responded more to light quality than old seedlings.

Flower development under photoselective films. 'Bright Golden Anne' and 'Yellow Snowdon' plants grown in the $\mathrm{A}_{\text {fr3 }}$ and $\mathrm{CuSO}_{4}$ chambers had fewer lateral branches than plants in other treatments (data not shown). Regardless of cultivar, plants produced in $\mathrm{A}_{\mathrm{fr} 1}$ and $\mathrm{A}_{\mathrm{fr} 2}$ chambers had about the same number of flowers as control plants (Table 2). 'Iridon' and 'Yellow Snowdon' plants in the $\mathrm{A}_{\mathrm{fr} 3}$ chamber had fewer flowers than the control plants. Generally, flowers of plants grown in photoselective film chambers were smaller than control plants. Except in 'Yellow Snowden', the smallest flowers were in plants grown inside $\mathrm{CuSO}_{4}$ chamber. Photoselective films did not significantly affect anthesis of any of the cultivars tested in this experiment.

It has been reported that FR light is needed for optimum flowering of some photoperiod sensitive species, especially the long day plants (Thomas and Vince-Pruce, 1997). In previous work, Rajapakse and Kelly (1995) reported that $\mathrm{CuSO}_{4}$ liquid filters delayed anthesis of 'Bright Golden Anne' chrysanthemum by 7 to $13 \mathrm{~d}$, depending on the season. In 'Spears' chrysanthemum, however, McMahon et al. (1991) reported that FR light deficient environments did not affect time to anthesis under inductive photoperiods but promoted flowering under less inductive, photoperiods compared to control plants. In 'Meijikatar' miniature roses, $\mathrm{CuSO}_{4}$ filters slightly accelerated (2 to $3 \mathrm{~d}$ ) anthesis of early spring grown plants, but slightly delayed ( 2 to $3 \mathrm{~d}$ ) anthesis of late spring- and summer-grown plants (Rajapakse and Kelly, 1994). In the present work, $\mathrm{CuSO}_{4}$ filter delayed anthesis of 'Bright Golden Anne' and 'Yellow Snowdon' by 6 and 4 d, respec- 


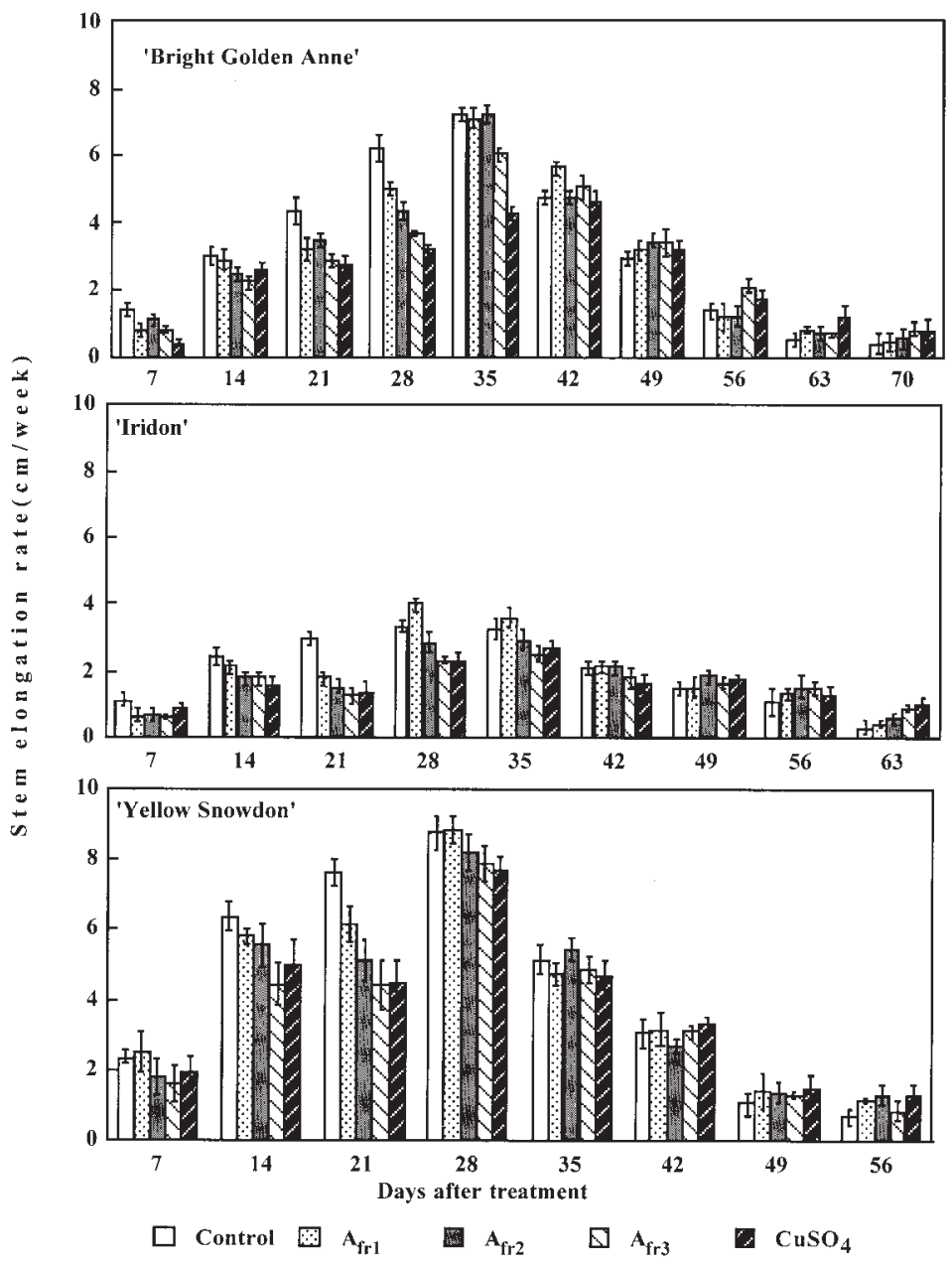

Fig. 1. Influence of photoselective films on weekly stem elongation rate of the three chrysanthemum cultivars. Control is clear film. $\mathrm{A}_{\mathrm{frr}}, \mathrm{A}_{\mathrm{fr} 2}$, and $\mathrm{A}_{\mathrm{fr} 3}$ are films with far red light absorbing dye with increasing order of dye concentration. The R:FR ratio and $\mathrm{P}_{\mathrm{fr}}: \mathrm{P}_{\text {total }}$ inside control, $\mathrm{A}_{\mathrm{fr} 1}, \mathrm{~A}_{\mathrm{fr}}, \mathrm{A}_{\mathrm{fr} 3}$, and $\mathrm{CuSO}_{4}$ chambers were $1.1,1.6,2.3,3.5$, and 3.7 , and were $0.72,0.75,0.78,0.81$, and 0.80 , respectively. Vertical bars indicate standard error.

Table 2. Influence of far-red light absorbing films on number of flowers, flower diameter, days to anthesis and height at flowering of three chrysanthemum cultivars. Data were taken after 7 weeks under treatments. Number in parenthesis followed by the plant height indicates the percentage of height relative to control plants at flowering.

\begin{tabular}{|c|c|c|c|c|c|}
\hline Treatment $^{2}$ & $\begin{array}{c}\mathrm{R}: \mathrm{FR} \\
\text { ratio }\end{array}$ & $\begin{array}{l}\text { No. of } \\
\text { flowers }\end{array}$ & $\begin{array}{c}\text { Flower diam } \\
(\mathrm{cm})\end{array}$ & $\begin{array}{l}\text { Plant height at } \\
\text { flowering }(\mathrm{cm})\end{array}$ & $\begin{array}{l}\text { Days to } \\
\text { anthesis }\end{array}$ \\
\hline \multicolumn{6}{|c|}{ Bright Golden Anne } \\
\hline Control & 1.1 & $17 \mathrm{a}$ & $9.8 \mathrm{a}$ & $38.2(100)$ & $60 \mathrm{~b}$ \\
\hline$A_{f-1}$ & 1.6 & $16 \mathrm{a}$ & $9.2 \mathrm{~b}$ & $36.4(95)$ & $60 \mathrm{~b}$ \\
\hline $\mathrm{A}_{\mathrm{fr} 2}^{\mathrm{fr} 1}$ & 2.3 & $16 \mathrm{a}$ & $8.5 \mathrm{c}$ & $35.3(92)$ & $61 \mathrm{~b}$ \\
\hline $\mathrm{A}_{\mathrm{fr} 3}$ & 3.5 & $13 \mathrm{a}$ & $8.7 \mathrm{c}$ & $33.5(88)$ & $63 \mathrm{ab}$ \\
\hline $4 \% \mathrm{CuSO}_{4}$ & 3.7 & $12 \mathrm{a}$ & $7.5 \mathrm{~d}$ & $31.5(82)$ & 66 a \\
\hline \multicolumn{6}{|c|}{ Iridon } \\
\hline Control & 1.1 & $15 \mathrm{a}$ & $7.1 \mathrm{a}$ & $21.0(100)$ & $56 \mathrm{a}$ \\
\hline$A_{\text {fr1 }}$ & 1.6 & $15 \mathrm{a}$ & $6.8 \mathrm{ab}$ & $21.3(101)$ & $56 \mathrm{a}$ \\
\hline $\mathrm{A}_{\mathrm{ft} 2}$ & 2.3 & $13 \mathrm{ab}$ & $6.5 \mathrm{~b}$ & $19.8(94)$ & $57 \mathrm{a}$ \\
\hline $\mathrm{A}_{\mathrm{fr} 3}$ & 3.5 & $13 \mathrm{ab}$ & $6.4 \mathrm{~b}$ & $19.5(93)$ & $56 \mathrm{a}$ \\
\hline $4 \% \mathrm{CuSO}_{4}$ & 3.7 & $11 \mathrm{~b}$ & $6.1 \mathrm{c}$ & $19.1(91)$ & $58 \mathrm{a}$ \\
\hline \multicolumn{6}{|c|}{ Yellow Snowdon } \\
\hline Control & 1.1 & $19 \mathrm{a}$ & $8.2 \mathrm{a}$ & $45.7(100)$ & $49 \mathrm{~b}$ \\
\hline$A_{f r 1}$ & 1.6 & $18 \mathrm{a}$ & $7.6 \mathrm{~b}$ & $44.5(97)$ & $50 \mathrm{ab}$ \\
\hline$A_{t+2}^{\text {IIt }}$ & 2.3 & $20 \mathrm{a}$ & $7.5 \mathrm{~b}$ & $40.4(88)$ & $51 \mathrm{ab}$ \\
\hline $\mathrm{A}_{\mathrm{fr} 3}$ & 3.5 & $14 \mathrm{~b}$ & $7.0 \mathrm{c}$ & $39.2(86)$ & $52 \mathrm{ab}$ \\
\hline $4 \% \mathrm{CuSO}_{4}$ & 3.7 & $14 \mathrm{~b}$ & $6.9 \mathrm{c}$ & $39.6(87)$ & $53 \mathrm{a}$ \\
\hline
\end{tabular}

${ }^{2}$ Control is clear film. $\mathrm{A}_{\mathrm{fr} 1}, \mathrm{~A}_{\mathrm{fr} 2}$, and $\mathrm{A}_{\mathrm{fr} 3}$ are films with far red light absorbing dye with increasing order of dye concentration.

yEach number is the mean of 20 plants. Mean comparison among treatments within a column by Duncan's multiple range test. $P=0.05$. Means followed by the same letter are not significantly different. tively, but did not affect anthesis of 'Iridon' suggesting that cultivars behave differently to filtered light. Photoselective films did not affect anthesis of any of the chrysanthemum cultivars tested in this experiment. The $\mathrm{CuSO}_{4}$ liquid filter absorbed almost all wavelengths beyond $700 \mathrm{~nm}$, but the photoselective films absorbed FR light with maximum absorption at $760 \mathrm{~nm}$ (Li et al., 2000). Therefore, the plants grown under $\mathrm{A}_{\mathrm{fr}}$ films received some FR light compared to plants grown under the $\mathrm{CuSO}_{4}$ filter and this may explain the differential response of 'Bright Golden Anne' and 'Yellow Snowdon' to photoselective films and the $\mathrm{CuSO}_{4}$ filters. Murakami et al. (1997) indicated that FR light intercepting films delayed the first harvest of cucumber and tomato by 3 and $2 \mathrm{~d}$, respectively. Cerny et al. (2000) reported that flowering of short day plants, zinnia (Zinnia elegans Jacq.), chrysanthemum, cosmos (Cosmos bipinnatus Cav.) and day neutral plant, Rosa $\times$ hybrida (day neutral plant) was not influenced by the FR light absorbing photoselective films and that photoselective films had the greatest influence on anthesis of long day plants, petunia (Petunia xhybrida Vilm.-Andr.) and snapdragon (Antirrhinum majus L.). Anthesis of snapdragon and petunia under the FR light absorbing film was delayed 7 and $13 \mathrm{~d}$, respectively, during noninductive photoperiods, but not affected during inductive photoperiods. vanHaeringen et al. (1998) also reported that snapdragon plants grown under a FR light absorbing film flowered $9 \mathrm{~d}$ later than the control plants.

In conclusion, FR light absorbing greenhouse covers were effective in reducing stem elongation of three chrysanthemum cultivars evaluated. Photoselective covers were most effective in reducing stem elongation during the early vegetative period. Following transition to the reproductive stage, weekly stem elongation rates were reduced and were similar among treatments. As a result, the difference in plant height at flowering between control and photoselective film grown plants was reduced. Although the films with higher dye concentration were more effective in reducing stem elongation of chrysanthemum, increased dye concentration reduced light transmission. Thus, we believe photoselective covers that reduce light transmission over $25 \%$ would not be suitable for commercial production. Under such covers, $15 \%$ to $20 \%$ stem length reduction, depending on cultivar, was achieved with chrysanthemum cultivars evaluated. Photoselective plastic covers did not affect anthesis, but slightly reduced flower size.

\section{Literature Cited}

Cerny, T., N.C. Rajapakse, S. Li, and R. Oi. 2000. Flowering of selected ornamental plants under photoselective greenhouse films. Proc. Natl. Agr. Plastics Congr. 29:177-185.

Li, S., N.C. Rajapakse, R.E. Young, and R. Oi. 2000. Growth responses of chrysanthemum and bell pepper transplants to photoselective plastic films. Scientia Hort. 84:215-225.

McMahon, M.J., J.W. Kelly, D.R. Decoteau, R.E. Young, and R.K. Pollock. 1991. Growth of Den- 
dranthema $\times$ grandiflorum (Ramat.) Kitamura under various spectral filters. J. Amer. Soc. Hort. Sci. 116:950-954.

Morgan, D.C. and H. Smith. 1976. Linear relationship between phytochrome photoequilibrium and growth in plants under simulated natural radiation. Nature 262: 210-212.

Morgan, D.C. and H. Smith. 1979. A systematic relationship between phytochrome-controlled development and species habit, for plants grown in simulated natural radiation. Planta 145:253-258.

Mortensen, L. M. and E. Strømme. 1987. Effect of light quality on some greenhouse crops. Scientia Hort. 33:27-36.

Murakami, K., H. Cui, M. Kiyota, Y. Takemura, R. Oi, and I. Aiga. 1996. Covering materials to control plant growth by modifying the spectral balance of daylight. Plasticulture 110:2-14. Murakami, K., H. Cui, M. Kiyota, Y. Takemura, R. Oi, and I. Aiga. 1997. Control of plant growth by covering materials for greenhouses which alter the spectral distribution of transmitted light. Acta Hort. 435:123-130.

Rajapakse, N.C. and J.W. Kelly. 1992. Regulation of chrysanthemum growth by spectral filters. J. Amer. Soc. Hort. Sci. 117:481-485.

Rajapakse N.C. and J.W. Kelly. 1994. Influence of spectral filters on growth and postharvest quality of potted miniature roses. Scientia Hort. 56:245-255.

Rajapakse N.C. and J.W. Kelly. 1995. Spectral filters and growing season influence growth and carbohydrate status of chrysanthemum. J. Amer. Soc. Hort. Sci. 120:78-83.

Rajapakse N.C., R.E. Young, M.J. McMahon, and R. Oi. 1999. Plant height control by photoselec- tive filters: Current status and future prospects. HortTechnology 9:618-624.

Sager, J.C., W.O. Smith, J.C. Edwards, and K.L. Cyr. 1988. Photosynthetic efficiency and phytochrome photoequilibria determination using spectral data. Transactions of ASAE 31:1882-1887.

Takaichi, M., H. Shimaji, and T. Higashide. 2000. Effect of red/far-red photon flux ratio of solar radiation on growth of fruit vegetable seedlings. Acta Hort. 514:147-156.

Thomas, B. and D. Vince-Pruce. 1997. Photoperiodism in plants. $2^{\text {nd }}$ ed. Academic, San Diego.

van Haeringen, C.J., J.S. West, F.J. Davis, A. Gilbert, P. Hadley, S. Pearson, A.E. Wheldon, and R.G.C. Henbest. 1998. The development of solid spectral filters for the regulation of plant growth. Photochem. Photobiol. 67:407-413. 